ISSN: 2238-8052

\title{
EL MOVIMIENTO ESTUDIANTIL EN CHILE Y LA PROPUESTA DEL CONTROL COMUNITARIO DE LA EDUCACIÓN
}

\author{
O MOVIMENTO ESTUDANTIL NO CHILE E A PROPOSTA \\ DO CONTROLE COMUNITÁRIO DA EDUCAÇÃO
}

Juan David Miranda GONZÁLEZ1

Tomás Elgueta TORO²

Artigo recebido em 24/05/2019 e aceito em 04/07/2019

Palabras clave:

Neoliberalismo.

Movimientos sociales.

Educación.

Control comunitario.

\section{R E S U M E N}

Existe a escala global un proceso de mundialización de la economía capitalista correspondiente al neoliberalismo, sin embargo, también se puede observar un proceso contra-hegemónico global que emerge desde los territorios en resistencia y que configura diferentes movimientos sociales que prefiguran alternativas en oposición a las medidas de austeridad, siendo la realidad latinoamericana un ejemplo de ello. En ese contexto, resulta importante analizar el movimiento estudiantil secundario chileno, pues se trata de un movimiento social que lucha contra el neoliberalismo en educación y que prefigura una educación distinta. El trabajo evidencia el control comunitario de la educación como una propuesta contra-hegemónica que reivindica el financiamiento estatal pero con una organización comunitaria, autónoma y horizontal.

\section{R E S U M O}

Palavras-chave: Neoliberalismo. Movimentos sociais. Educação. Controle comunitário.

Há um processo global de mundialização da economia capitalista correspondente ao neoliberalismo, no entanto, também se pode observar um processo contra-hegemônico global que emerge dos territórios em resistência e que configura o desenvolvimento de diferentes movimentos sociais que prefiguram alternativas em oposição às medidas de austeridade, sendo a realidade da América Latina um exemplo disso. Neste contexto, é importante analisar o movimento estudantil secundarista chileno, pois se trata de um movimento social que luta contra o neoliberalismo na educação e que prefigura uma educação diferente. 0 trabalho evidência o controle comunitário da educação como uma proposta contra-hegemónica que reivindica o financiamento estatal, mas com uma organização comunitária, autónoma e horizontal.

\section{INTRODUCCIÓN}

El proceso de globalización puede ser interpretado como el desarrollo paralelo de dos fenómenos. El capitalismo en su fase neoliberal correspondiente a la mundialización de la economía produjo transformaciones profundas en el conjunto de la sociedad pero, a su vez, se evidencia el crecimiento de protestas a nivel global que se oponen al neoliberalismo siendo interpretado como

\footnotetext{
1 Mestrando en Edcación de la Universidade Estual de Campinas. Profesor de Educación General Básica titulado de la Universidad de Santiago de Chile. E-mail: juanmg.1985@gmail.com.

2 Estudiante de Educación Diferencial. Universidad Metropolitana de las Ciencias de la Educación. Chile. E-mail: tomas.elguetat@gmail.com.
} 
resistencias contra-hegemónicas. La mundialización de la economía está caracterizada, fundamentalmente, por dos aspectos; primero, la hegemonía de las empresas transnacionales que dirigen los rumbos económicos y políticos de los países y; segundo, una crisis política del sistema representativo debido a que los gobiernos perdieron la posibilidad de determinar de forma autónoma los caminos de los Estados.

La hegemonía mundial del mercado ha logrado ser aplicada en los distintos países a través de las políticas impuestas por el Fondo Monetario Internacional y el Consenso de Washington que consisten en la privatización de los derechos sociales y la desreglamentación de los mercados. Así, la combinación de una crisis económica y política ha producido un proceso de protestas populares a nivel mundial, procesos que pese a no estar conectados, si poseen aspectos en común.

América Latina, particularmente Chile, fue uno de los primeros lugares en donde esa realidad comenzó a ser configurada. Primero a través del cambio del modelo de producción, esto es el paso del modelo de sustitución de las importaciones por el sistema monoproductor de materias primas y, posteriormente, la modernización del Estado y las privatizaciones de los derechos. Dada la agudización de las desigualdades generadas por el modelo los sectores populares, los sin derechos, se organizaron para resistir a los recortes económicos configurando en algunos territorios una realidad social y política en resistencia. Esta nueva realidad política y social puede ser interpretada como la globalización contra-hegemónica, pues si bien en Latinoamérica se desarrolla desde la década de los 80', a nivel mundial diferentes movimientos sociales comienzan a presentar características similares.

Los distintos sectores organizados y que protestan contra los recortes económicos pueden ser estudiados desde las teorías de los movimientos sociales, fundamentalmente, desde la Política de Conflicto. Esta perspectiva señala que las acciones colectivas para ser comprendidas como movimientos sociales deben poseer tres aspectos comunes relacionados por medio del conflicto político entre sus actores. Si bien, esta corriente nos aporta varios conceptos significativos para el estudio de las acciones anti-neoliberales, también resulta limitada, pues se desarrollan en un contexto diferente marcado por la globalización y la reconfiguración de los Estado nación.

Los movimientos contra-hegemónicos, si bien poseen la relación política contenciosa señalada por la Política de Conflicto, resulta limitada dado que no consigue explicar un nuevo elemento que algunos teóricos proponen correspondiente a la prefiguración de una sociedad distinta a la capitalista. Por este motivo, resulta importante considerar los aportes desarrollados desde la perspectiva latinoamericana que profundiza, entre otros aspectos, en las tendenciosas cotidianas que es posible observar en las organizaciones sociales en resistencia.

En ese contexto global de crisis económica y política que enfrentan las resistencias contrahegemónicas podemos ubicar el movimiento estudiantil secundario chileno. Es posible hacer esta relación ya que en el movimiento se desarrollan ambos procesos, es decir, los estudiantes enfrentan 
los recortes económicos y la configuración de un sistema educativo mercantilizado pero, también vienen desarrollando una serie de acciones colectivas que pueden ser interpretadas como resistencias contra-hegemónicas al neoliberalismo educativo.

Comprendiendo entonces el movimiento secundario chileno post-dictadura como un movimiento anti-neoliberal y las experiencias en resistencia desarrolladas en su interior ¿Cuál es la educación contra-hegemónica que están prefigurando? Con el objetivo de identificar la prefiguración de otra educación y sus características en el interior del movimiento secundario, se desarrollará un análisis bibliográfico y documental cualitativo para demostrar que la propuesta del control comunitario y de algunas experiencias de educación popular ancladas al movimiento podrían ser interpretadas como resistencias que prefiguran otra educación.

Los principales resultados del trabajo son la comprensión del movimiento estudiantil como un fenómeno social que se está configurando de forma constante desde la dictadura y que se levanta contra la educación mercantilizada. También la evidencia que el movimiento ha sido capaz de profundizar sus demandas gracias a la configuración de experiencias de acciones colectivas educativas cotidianas pero que se hacen públicas en los procesos de ebullición política. Finalmente, la propuesta del control comunitario de la educación puede ser interpretada como síntesis del largo proceso social y político desarrollado por los secundarios y que evidencia una suerte de tendencia educativa contrahegemónica basada en lógicas más allá del capitalismo y el Estado.

Sin duda se trata de un proceso histórico y, por ende, en transformación, por lo que aventurarse a señalar conclusiones finales resulta inapropiado. Sin embargo, un claro desafío puede ser cómo seguir avanzando en la superación del modelo hegemónico y, a su vez, avanzar en la incorporación de otras demandas sociales de carácter educativo como las levantadas por el movimiento feminista correspondiente a una educación no sexista.

\section{NEOLIBERALISMO Y MOVIMIENTOS SOCIALES}

El proceso económico que se desarrolla a escala global en la actualidad no tiene sólo una dirección, pues se evidencian dos ondas paralelas y relacionadas dialécticamente. Este proceso consistente en una reestructuración del capitalismo que influye en todos los campos sociales, no obstante, también se observan en diferentes lugares del mundo procesos heterogéneos de resistencia a esa reestructuración capitalista.

Como dice Marques y Lucon (2017):

Se puede verificar la presencia de al menos dos procesos de globalización simultáneos: el proceso de globalización hegemónica y el proceso de globalización contra hegemónico. El primero está relacionado con la búsqueda de hegemonía por parte del poder de las corporaciones internacionales, de los países hegemónicos, principalmente Estados Unidos. En el campo de las ideas también busca 
hegemonizarse con el pensamiento neoliberal, con su creencia en el mercado como centro de la sociabilidad y en el individuo consumidor y maximizador como ente fundamental de la sociedad. El proceso de globalización contra hegemónico busca alternativas al poder hegemónico creando un debate y un movimiento internacional en favor de la diversidad cultural, de la defensa del medio ambiente, de los derechos y garantías sociales, de la democracia radical, de los derechos de las mujeres, del movimiento LGBT y algunos llegan a anhelar la transición hacia otra sociabilidad, como es el caso del movimiento eco-socialista y de tantas otras organizaciones y colectivos de izquierda (p. 196-197, traducción nuestra).

En otras palabras, se están desarrollando dos procesos paralelos en disputa correspondientes a la globalización económica de carácter hegemónico y otro proceso de carácter contra-hegemónico consistente en las resistencias al capitalismo. Estos dos procesos afectan a la sociedad en su conjunto, no obstante, en este artículo nos centraremos en cómo este proceso es evidenciado en el campo educativo y así contextualizar históricamente la propuesta de control comunitario que desarrollan los estudiantes secundarios en Chile.

La globalización, según la interpretación propuesta por Marques y Lucon (2017), es un conjunto fenómenos que tienen relación con un proceso de reordenación capitalista, específicamente, medidas político-económicas en respuesta a la crisis estructural que vivencia el capitalismo desde la década de los 70'. Esas medidas básicamente consisten en la liberalización, desregulación y privatización con el objetivo de devolver al capital la libertad perdida a comienzos del siglo XX. Esto quiere decir que estamos frente a un proceso de mundialización del capital que se viene poniendo en práctica a través del neoliberalismo que pasó a determinar la política interna de los países.

Este mismo proceso es descrito por Oliveira (2006) de la siguiente forma:

Los intereses internos son mediados por los recursos globales de capitales y de política. En una palabra, la dominación de clase fue extrovertida [...] Al abrirse la mediación política de la política, esta dejó de existir como nacionalidad, pues los conflictos internos ya no tienen ninguna capacidad de producir políticas ni siquiera de arbitrarlas. Los partidos, pues, no solo cumplen un plan previsto por Michels, ellos rigurosamente no hacen más la política. Y se consumen en una lucha por el poder que no tiene nada de programática (p. 286, negrita del autor, traducción nuestra).

Así, un primer sentido de este proceso de globalización está caracterizado por la interacción de lo político y de lo económico que produce las contradicciones globales para que el capital pueda tener una movilidad libre y sin restricciones. Consecuencia de esta interacción los países pasan a configurar verdaderas democracias de mercado dirigidas por los capitales externos donde el interés de las personas ya no tienen espacio generando de ese modo una crisis de legitimidad de los sistemas políticos representativos.

Por otra parte, el proceso contra-hegemónico, aunque aún es difuso, en el año 2011 quedó en evidencia debido a que ocurrió un fenómeno que no se veía hacía mucho tiempo. Una explosión de diferentes movimientos sociales y en distintas partes del mundo con demandas específicas en cada región, pero utilizando estrategias de lucha similares y una solidaridad mutua adquiriendo esta ola de protestas sociales una dimensión global (SOARES, 2012). Sin embargo, este proceso viene gestándose 
hace varias décadas y comenzó primero en la periferia, después en la semi-periferia y, actualmente, se desarrolla también en el centro del capitalismo (DELLA PORTA, 2015).

La misma autora define estos movimientos como Anti-austeridad, pues todos ellos tienen en común la oposición a los recortes de derechos sociales generados por el neoliberalismo pero también la puesta en práctica de lógicas anticapitalistas; democracia directa, horizontalidad y autogestión de las estrategias de lucha. No obstante, resulta importante mencionar que se trata de prácticas limitadas, pues solo logran ponerse en práctica durante la ebullición del movimiento social, principalmente, en las ocupaciones o tomas de espacios públicos y enfrentan una serie de problemas internos (DELLA PORTA, 2015).

La disputa entre estos procesos se desarrollan en América Latina desde hace varias décadas por lo que las luchas contra-hegemónicas poseen mayor experiencia y trayectoria resultando importante revisarlas para profundizar las lecturas de los elementos apuntados por Della Porta, pues talvez, los movimientos sociales latinoamericanos nos entreguen más herramientas para comprender y avanzar en la construcción de una sociedad que supere las injusticias del capitalismo.

El proceso neoliberal en esta parte del mundo comenzó en la década de los 80, a excepción de Chile donde se inició de manera experimental en la década del 70'. La primera etapa consistió en el cambio del paso del modelo de sustitución de las importaciones por la promoción de las exportaciones de materia prima, atapa impuesta por las negociaciones con el Fondo Monetario Internacional y que generó una profunda crisis económica. Una vez que las economías mostraron una estabilidad relativa, esto es control de la inflación y una leve recuperación, se aplicó una segunda etapa de profundización consistente en la modernización del Estado y la privatización de los servicios sociales, medidas impuestas por el Consenso de Washington que se basaban en al caso chileno (OLAVE, 2003).

Así, la oleada neoliberal al modificar las formas de producir provocó una profunda transformación en la vida cotidiana de los sectores populares, pues dividió los mecanismos de reproducción territoriales y simbólicos que le daban unidad (ZIBECHI, 2003). Como consecuencia de este proceso en toda Latinoamérica surgieron:

Los movimientos de los "sin" (sin techo, sin tierra, sin derechos, sin trabajo), o sea, los movimientos de los que perdieron con el neoliberalismo, ocupan el centro del escenario social y son los responsables de la nueva relación de fuerzas que atraviesa el continente, desde la comuna de Oaxaca, México, hasta la fábrica recuperada Zanón, en la Patagonia (ZIBECHI, 2011, p. 9).

La nueva relación de fuerzas señalada por el autor uruguayo constituyó una realidad y movimientos sociales con características distintas a las de otras partes del mundo, siendo un ejemplo de ello desafiando a las corrientes teóricas que estudiaban los movimientos sociales hasta ese momento. En otras palabras, mientras en Estados Unidos y Europa emergían movimientos sociales que eran estudiados, principalmente, a partir de la Teoría del Proceso Político y de los Nuevos 
Movimientos Sociales, estas resultaban insuficientes para conseguir una comprensión crítica de lo que sucedía en América Latina.

Aunque, los trabajos desarrollados desde la perspectiva de Proceso Político dejaron saldos significativos, los primeros estudios que asumieron la tarea de enfrentar la realidad latinoamericana mostraron que:

Lo que se intuye es una nueva forma de relacionar lo político y lo social, el mundo público y la vida privada, en la cual las prácticas sociales cotidianas se incluyen junto a, y en directa interacción con, lo ideológico y lo institucional-político (CALDERÓN; JELIN, 1987: p. 177).

De esta manera, antes de analizar el movimiento social por la educación y comprender la propuesta del control comunitario desarrollada por los estudiantes secundarios en Chile, resulta necesario realizar una revisión de la Contentious Politics (Política de Conflicto) y los Movimientos Latinoamericanos e intentar una aproximación de estas, pues nos aportan elementos teóricos importantes para comprender críticamente nuestro objeto de estudio.

\section{LA POLÍTICA DE CONFLICTO Y LOS MOVIMIENTOS LATINOAMERICANOS}

Las diferentes perspectivas de estudio de los movimientos sociales nos ofrecen posibilidades diversas para entender el problema, pues se esfuerzan por entender estos fenómenos sociales a partir de foco diferentes existiendo como consecuencia diferentes interpretaciones de lo que puede ser entendido como un movimiento social. No obstante, existen algunos autores que intentaron proponer una conceptualización amplia de movimiento social para así abarcar una mayor cantidad de experiencias. Por otro lado, desde la década de los 80' diferentes intelectuales latinoamericanos han intentado mirar las prácticas y acciones desarrolladas por las sociedades en conflicto con el neoliberalismo colocando otras problemáticas. Por esta razón, antes de analizar el movimiento de estudiantes resulta importante identificar un campo conceptual, aunque problemático, pero que nos posibilite una aproximación crítica de nuestro objeto de estudio.

Según Alonso (2009) existen tres grandes perspectivas para estudiar los movimientos sociales correspondientes a la teoría de movilización de recursos (TMR), la teoría del Proceso Político (TPP) y la teoría de los Nuevos Movimientos Sociales (TNMS), sin embargo, las dos últimas han sido las más utilizadas en la producción científica de este campo. Por otro lado, tanto la TPP como la TNMS tienen en común que se oponen a las interpretaciones de carácter marxista, deterministas y economicistas, proponiendo la relación de lo político y lo cultural en sus análisis, centrándose la primera en una teoría de movilización política y, la segunda, en una teoría de cambios culturales.

Para Charles Tilly (2010), principal referente de la TPP, un movimiento social relaciona tres elementos centrales: 
Un esfuerzo público sustentado en la elaboración de reivindicaciones colectivas dirigidas a determinadas autoridades (esfuerzo que puede ser llamado campaña); El empleo de combinaciones dentro de las siguientes formas de acción política: creación de asociaciones y coaliciones para finalidades específicas, reuniones públicas, desfiles solemnes, vigilias, comicios, demostraciones, iniciativas reivindicatorias, declaraciones para y en los medios de comunicación de masa, y panfleteo (ese conjunto variable de actividades puede ser llamado de repertorio de los movimientos sociales; e representaciones públicas concertadas de VUNC (Valor, unidad, números y compromiso) por parte de los participantes [...] Lo que constituye un movimiento social no son apenas las acciones de los demandantes, los objetos de demanda o el público, sino que la interacción de esos tres elementos (p. 136 - 137, traducción nuestra).

De lo propuesto por Tilly se rescata que un movimiento social está compuesto por la relación existente entre una campaña, un repertorio y la concentración de VUNC, sin embargo, el elemento central de los movimientos sociales según la TPP se encuentra en el conflicto político que desarrollan, pues este es el elemento que relaciona los tres componentes. Esta idea se infiere también de la cita anterior, pues los movimientos sociales construyen demandas colectivas dirigidas a las autoridades $\mathrm{u}$ otro actor generando un conflicto.

El conflicto político como elemento característico de los movimientos sociales lo evidencia de mejor forma Tarrow (1997) al señalar que la "acción colectiva contenciosa" corresponde a la base del movimiento social, pues a través de esta los sujetos sin poder logran enfrentarse de manera más equitativa a los adversarios detentores del poder.

Evidentemente, esta perspectiva nos proporciona elementos significativos para analizar los movimientos sociales, como puede ser el concepto de repertorio y otros que revisaremos más adelante. Sin embargo, también ya se reconocía una dificultad de esta frente al escenario globalizado que emergía:

Así como el movimiento social se difundió con el desarrollo de Estados centralizados relativamente democráticos, la descentralización gubernamental, la extensiva privatización de las actividades gubernamentales, el eclipse del Estado por las potencias transnacionales o la extensiva des-democratización podrían, todas ellas, eliminar de la escena política los movimientos sociales tal como los conocemos hoy. De hecho, con la ocurrencia del conjunto de cambios que las personas llaman vagamente de "globalización", los ciudadanos que cuentan con los movimientos sociales para hacerse escuchar necesitan preocuparse seriamente con el futuro (TILLY, 2010, p. 152, traducción nuestra).

Pese a esta dificultad, creemos que es posible rescatar desde esta perspectiva otros dos conceptos que nos permitirían comprender de mejor forma la experiencia estudiantil, y los movimientos sociales contra-hegemónicos en general, estos conceptos son: las oportunidades políticas y las estructuras de movilización, aunque tensionadas por la realidad neoliberal.

Las oportunidades políticas, según la Política de Conflicto, es un concepto central debido a que: 
El surgimiento y éxito de los movimientos sociales dependían, en gran medida, de las oportunidades políticas al alcance de los contestatarios, generadas por mudanzas en la estructura institucional e de la disposición ideológica de los grupos en el poder (MCADAM, 1999, p. 50).

No obstante, el mismo autor pone en advertencia que en un comienzo el término al ser usado de forma amplia y de diferentes formas tuvo dificultades para su limitación. Una de estos problemas fue el uso de oportunidades políticas entendidas como "cualquier factor del entorno que catalizara la acción de un movimiento" (Ibid, p. 51).

Las estructuras de movilización son interpretadas como las diversas organizaciones consensuadas, formales o informales, que el movimiento posee para implementar desde las distintas acciones colectivas, hasta los repertorios que desarrolla en su interior (MCCARTHY, 1999). Pero creemos que lo interesante del concepto consiste en la comprensión de los núcleos socioculturales cotidianos de micromovilización, es decir, aquellos grupos donde la principal función no es la movilización, aunque ella puede surgir de las bases; desde las unidades familiares hasta organizaciones o elementos parte de la estructura estatal propuestos por el mismo autor.

Desde la perspectiva latinoamericana, una característica central de los movimientos sociales es que ya no solo se centran solo en lo reivindicativo, sino que en las experiencias concretas que desarrollan en el interior de los espacios autónomos construidos fuera del control de las organizaciones tradicionales como los partidos políticos, las iglesias y los sindicatos (ZIBECHI, 2011).

En la misma línea que Zibechi, Raquel Gutiérrez (2011) denomina esos espacios como Entramados Comunitarios, que corresponden a sujetos colectivos diversos que se configuran fuera de las lógicas de producción capitalista. La misma autora reconoce de esta forma dos tipos de organizaciones correspondientes a: una política estadocéntrica y una autonomía política no centrada en el estado. Mientras la primera mantiene la lógica del movimiento que tiene por objetivo tomar el poder gubernamental, la autonomía política no centrada en el Estado representada en los entramados comunitarios:

[...] reinstala la decisión soberana deliberada en común sobre ámbitos específicos de la vida cotidiana, como eje práctico de su acción [...] tendencialmente es horizontal o, más bien, horizontalizadora en tanto que anti-jerárquica y anti-vertical [...] no puede quedar aprisionada en la dicotomía "estado/no estatal" (GUTIÉRREZ, 2011, p. 31 32).

Podemos observan cierta similitud entre los espacios autónomos y las estructuras de movilización, aunque los movimientos contra-hegemónicos se alejan del concepto propuesto por la Política de Conflicto ya que ensayan al interior de los entramados comunitarios la sociedad que desean pero de manera limitada, en palabras de Zibechi (2011) "prefiguran". Así, las acciones colectivas prefigurativas incorporan la evidencia de un potencial emancipatorio en desarrollo y transformación.

Consecuentemente, resulta necesario estudiar los movimientos contra-hegemónicos como fenómenos sociales históricos, o sea, dinámicos y en transformación. Zibechi (2007) tras estudiar 
diversas experiencias latinoamericanas observó que es posible identificar algunas "tendencias" comunes en América Latina: autonomía tanto del Estado y de los partidos políticos; la revalorización de su cultura y de una identidad ligada a sus pueblos y sectores sociales; la auto-educción y autoformación de sus intelectuales; una función central de las mujeres; relaciones laborales igualitarias y horizontales en armonía con la naturaleza y; la reapropiación material y simbólica de los espacios, esto es las ocupaciones o tomas.

\section{CHILE POST-DICTADURA: EDUCACIÓN NEOLIBERAL Y EL MOVIMIENTO ESTUDIANTIL SECUNDARIO}

El neoliberalismo en Chile se comienza a imponer durante la dictadura de Pinochet al final de la década de los 70' y tuvo dos líneas centrales; la violencia del contexto dictatorial y la transformación profunda de la sociedad chilena rompiendo con el modelo desarrollado desde 1930.

La política de "shock" fue destinada a transformar de manera radical (es decir a la raíz) las fronteras establecidas entre poder político, Estado y campo económico para terminar definitivamente con el Estado capitalista "de compromiso" de los años 30-70 (GAUDICHAUD, 2015, p. 15)

Una primera parte de esta oleada neoliberal consistió en deshacer las reformas hechas por el gobierno de la UP, fundamentalmente, los avances en la estatización de empresas. Posteriormente, la segunda etapa correspondió a la reforma política del Estado que se registró a partir de 1979 a través de las siete modernizaciones referentes al proceso de reforma administrativa consistente en la regionalización y municipalización, el plan laboral, la privatización de la educación; de la vivienda; de la salud; la previsión y, finalmente, la modernización del sistema jurídico (GAUDICHAUD, 2015).

En el ámbito educativo este modelo significó la estructuración de un sistema basado en: 1) la redefinición del marco regulatorio de la educación, o sea, la función del Estado y la comprensión de los derechos educativos a través de una nueva constitución; 2) gestión del sistema educativo que entrega importancia central a los sostenedores correspondientes a los municipios y privados; 3) financiación de las escuelas a través de un sistema de vouchers o subsidios a los estudiantes y, por último; 4) reestructuración y privatización del sistema de educación superior (ASSAÉL et al., 2011).

La Constitución impuesta en el año 80 en materia educativa redefine la educación dejando de ser función primordial del Estado pasando a ser los padres quienes tienen el derecho de elegir dónde se educan los hijos y es responsabilidad del Estado garantizar la protección de ese derecho. También establece la libertad de enseñanza, es decir, la posibilidad de abrir, organizar y mantener establecimientos educativos y el derecho de los padres a elegir la escuela para los hijos (ASSAÉL et al., 2011).

Existe un consenso de que esas reformas neoliberales, primero; significaron la fundación de un modelo político, económico y social nuevo y, segundo; que el sistema educativo chileno al ser 
desarrollado sin argumentos ni evidencias empíricas que mostraron las consecuencias de él, puede ser considerado un experimento neoliberal impuesto por la dictadura (REDONDO, 2005).

Consecuencia de ello, existe la comprensión de la educación como una mercancía y los alumnos y padres como consumidores donde sus necesidades son satisfechas por el mercado educativo. La escuela entendida como una empresa orientada por las lógicas de la evaluación y la competencia es estructurada por tres ejes: en primer lugar, un proceso privatización de las escuelas; segundo, el accountability educativo o rendición de cuentas producto del énfasis en la calidad y la presión por la eficacia y racionalización y; tercero, la creación de rankings y la sanción por medio de evaluaciones estandardizadas (VILLALOBOS; QUARESMA, 2015).

Además, continuando con lo expuesto por Villalobos y Quaresma (2015), se evidencia el aumento de la segregación escolar que se produce desde los primeros años de escolaridad, también una segregación territorial en el sentido que los barrios con mejor situación económica poseen escuelas de mejor calidad. Por otro lado, y contrariamente a la libertad de las familias de elegir la escuela para sus hijos, son las escuelas por medio de rigurosos procesos selectivos la que acaban escogiendo a los alumnos.

Finalmente, este modelo de mercado educativo, además de generar cambios en los sistemas y las políticas educativas, también provocó transformaciones dentro de las escuelas y sus comunidades, pues "esta cultura de evaluación no se focaliza en los procesos pedagógicos sino en los resultados, lo cual ha provocado profundos cambios en los sistemas educativos y significativas reconfiguraciones en los ethos de las escuelas" (VILLALOBOS; QUARESMA, 2015, p. 66).

Todos esos cambios fueron generando múltiples injusticias en el sistema educativo, en las escuelas, en las condiciones de trabajo de los profesores, en las condiciones de enseñanza de los alumnos, etc. Injusticias que fueron criticadas tempranamente por los estudiantes secundarios y que, tras varios años de lucha y auto-educación, fueron entendiendo el sistema en su conjunto, profundizando sus demandas y comprendiendo que el movimiento social debía construir la educación que soñaba, pues nadie más lo haría por este. Debido a ello, resulta fundamental estudiar el movimiento en su conjunto e históricamente para comprender la propuesta del control comunitario de la educación.

\section{EL MOVIMIENTO ESTUDIANTIL SECUNDARIO}

El movimiento social por la educación que se está desarrollando en Chile y que se expresó más fuertemente en 2011 es importante porque es el primer movimiento social post-dictadura (19731990) que pone en discusión las cuestiones estructurales del país (DUARTE, 2013). Además, debe ser entendido como parte de un proceso histórico que tiene sus raíces más cercanas en la experiencia 
desarrollada por el mundo juvenil en las jornadas de protesta nacional contra la dictadura cívicomilitar y durante la transición a la democracia. De este modo, es posible afirmar que este movimiento social está ligado a un proyecto histórico popular truncado por las élites décadas antes (OBSERVATORIO CHILENO DE POLITICAS EDUCATIVAS [OPECH], 2014).

El final de la dictadura chilena a través de un plebiscito acordado por un pacto entre las élites militares y políticas tuvo como consecuencia que toda una generación de organizaciones juveniles y su experiencia fueran desplazadas, ocultas y marginadas de la política (DUARTE, 2013). Pero también las estructuras políticas tradicionales se retiraron de los territorios, situación que fue aprovechada por los jóvenes que comenzaron a articularse en pequeños grupos de carácter cultural que desarrollaron lógicas de construcción política desde abajo. Son organizaciones que privilegian la horizontalidad, la transparencia de la información, la autogestión y la independencia en relación a las instituciones e instituciones externas, aunque instrumentalizan algunas de ellas para obtener recursos económicos (MUÑOZ, 2002, p. 56).

Por otro lado, también una consecuencia del régimen militar y de la Constitución Política impuesta, se generó una crisis de legitimidad política. Como dice GARCÉS (2012):

Los problemas de legitimidad del sistema político chileno, en rigor, se comienzan a configurar en dictadura y se termina de construir en la transición a la democracia. Crisis en el sentido de la capacidad de la política del Estado para entender las demandas ciudadanas, algunas recientes y otras de vieja data (GARCÉS, 2012, p. 16 17).

Y como se dijo anteriormente, se impuso un sistema económico que comercializa la educación y se materializa a través de una ley constitucional que reconoce el derecho a la libertad de educación sobre el derecho a la educación, una ley de subsidios educativos que permite el lucro de la iniciativa privada con recursos públicos y la municipalización de las escuelas que delega la responsabilidad del Estado a los municipios (OPECH, 2010).

El movimiento estudiantil secundario en la década de 1980 organizado en la Federación de Estudiantes Secundarios de Santiago (FESES) desempeñó un papel relevante en la lucha contra la dictadura, ya que eran ELLOS los que enfrentaban el Estado en el centro de la capital, mientras los sectores populares lo hacían a partir de sus territorios en la periferia de la ciudad. Sin embargo, después del fin de la dictadura, la organización estudiantil secundaria tuvo una ruptura entre sus bases y líderes que llevaron a un período de desmovilización y que sólo fue superado una década después con la creación de grupos coordinadores de estudiantes (OPECH, 2010).

La FESES, principal entidad representativa de los estudiantes, sufrió una profunda crisis durante la década de los 90' que distanció a los líderes de sus las bases por dos razones; por un lado, porque los primeros dejaron de representar los intereses estudiantiles y atendían a los partidos políticos que pertenecían y; por otro, fueron financiados por agencias estatales generando una falta de transparencia. De esta forma, los centros de alumnos en los liceos eran deslegitimados por los 
estudiantes debido a que eran organizaciones cooptadas por las direcciones, los profesores y los partidos políticos, perdiendo su importancia representativa del estudiantado (INZUNZA, 2009).

La crisis política terminó cuando diferentes colectividades populares periféricas trajeron a la asociación toda una carga histórica de aprendizaje construida desde la lucha contra la dictadura y que se caracterizaba por la horizontalidad, un trabajo territorial y un activismo político que rechaza las estructuras tradicionales y los partidos políticos que impulsó la creación de la Asamblea Coordinadora de Alumnos del Secundario - ACES (SILVA, 2007).

En 2001, estalló el conflicto por el pase escolar, más tarde llamado mochilazo, coyuntura en la que los estudiantes hicieron público un repertorio que se creía haber desaparecido (OPECH, 2010). Como en la dictadura, los estudiantes se movilizaron a través de huelgas, marchas y barricadas por las calles de Santiago para exigir el paso escolar gratuito, el Estado intentó negociar con la juventud de los partidos políticos, pero su estrategia falló porque la mayor parte del el movimiento ya no estaba dirigida por los representantes, sino que se coordinaba horizontalmente y con portavoces autónomos. De esta forma, los estudiantes secundarios lograron el pase escolar libre y nacionalizaron, dentro de un sistema de gestión privada de transporte colectivo, la administración del pase escolar (OPECH, 2010).

En los años siguientes, el movimiento secundario inicia un nuevo proceso de desarrollo interno, fortalecimiento organizacional y de auto-formación política. Este proceso culmina en 2005 cuando, aprovechándose de una movilización universitaria, inicia una mesa de trabajo con el gobierno que tenía como diagnóstico común la necesidad de revisar los ejes centrales del sistema educativo, así se abre la posibilidad de diálogo con el gobierno. La coyuntura de 2005 sería el preludio para el movimiento del año siguiente, conocido como la Revolución del Pingüina.

El primer gobierno de Bachelet (2006 - 2010) contrariamente al diagnóstico del gobierno anterior, propuso en materia educativa el aumento del valor de la Prueba Universitaria de Selección (PSU), la reducción del uso del pase escolar para apenas dos veces al día y cambios en el cronograma de este. En respuesta, los secundarios iniciaron otro ciclo de protestas que mostró los resultados del proceso de desarrollo interno al reclamar una serie de demandas que cuestionaban el sistema educativo como un todo (GUTIÉRREZ; CAVIEDES, 2010). Pero, debido a la intransigencia del gobierno, los estudiantes desarrollan una forma más radical de movilización y empiezan a tomarse los establecimientos, las ocupaciones de los liceos empiezan en la capital y en pocos días son de carácter nacional (GUTIÉRREZ; CAVIEDES, 2010; OPECH, 2010).

Producto de la experiencia de los liceos en toma de ese año, se podría afirmar:

Que el movimiento cambió la cotidianeidad en las escuelas y la visión que la sociedad venía construyendo de los jóvenes, pero por sobre todo el cuestionamiento al sentido común neoliberal; el mercado y sus lógicas se vieron cuestionados. Podríamos afirmar que la movilización de los estudiantes secundarios significó el más importante proceso de incidencia de un actor social en políticas educativas, en el Chile de post- 
dictadura. Se trató de una incidencia global, en los tres grandes ámbitos de la sociedad: económico, político y cultural-ideológico (GONZÁLEZ, 2009, p. 417).

Más tarde, el año 2011 fue marcado por la llegada democrática de la derecha al gobierno después de 50 años y por el surgimiento de diferentes movimientos sociales. Como se esperaba, el gobierno continuó profundizando el neoliberalismo educativo desarrollado de forma constante desde la dictadura a través de medidas como aumento de recursos públicos para escuelas particulares, el cierre de escuelas municipales, el aumento de evaluaciones estandarizadas, entre otros (CENTRO ALERTA; OPECH, 2012) Los alumnos comenzaron a ocupar los liceos organizándolos a través de democracias directas en asambleas desarrollando una experiencia educativa autónoma, horizontal y autogestionada en su interior (VALENZUELA, 2012).

A modo de síntesis, se puede afirmar que el movimiento social puede ser interpretado como un movimiento anti-neoliberal e históricamente relacionado con el fin de la dictadura (GARCÉS, 2012), pero también, y desde otra perspectiva, el movimiento por medio de las tomas demostró, no sólo cuestionar el modelo educativo, sino que intentar poner en práctica la educación con la que soñaban y luchaban desde hace años (ZIBECHI, 2014).

Un año después, el movimiento secundario también fue capaz de elaborar diferentes propuestas educativas a partir de las discusiones, reflexiones y experiencias desarrolladas en todo este proceso. Si bien, todas estas propuestas también evidencian los conflictos existentes al interior del movimiento, destacamos la propuesta del control comunitario de la educación pues genera una disputa política desde la experiencia desarrollada desde abajo (ACES, 2012). Además, se trata de una propuesta que se configura desde los territorios y la auto-educación popular que rescata la importancia de la comunidad como un actor resolutivo en la educación. El control comunitario también tensiona la discusión en torno a lo público y de calidad, pues estos ejes quitan el foco de una crisis aún más profunda, la del sentido de la educación (FAURÉ, 2016).

De esta forma, es posible afirmar que el movimiento estudiantil secundario desde la lucha contra la dictadura desarrolla una relación política y social en sus procesos internos y externos. El desarrollo político está caracterizado porque tempranamente se levantó contra las políticas privatizadoras de la dictadura y, aunque durante los primeros años de la transición a la democracia, experimentó una crisis interna, logró retomar su lucha histórica pasando desde las demandas coyunturales o economicistas como lo era la lucha por el pase escolar a las críticas estructurales al sistema educativo.

La relación de carácter social que identificamos consiste en el desarrollo de sus estructuras de movilización y en su capacidad para reconfigurarse tras la crisis de la década del 90'. El movimiento estudiantil logró superar su carga histórica tradicional dejando atrás la dependencia de los partidos políticos y las limitaciones de las estructuras jerárquicas para avanzar en la consolidación de una 
plataforma de lucha autónoma, horizontal y autogestionada que le permitió relacionarse con el mundo social y construir experiencias de lucha colectiva que vinculan lo político y social.

Así, lo político dentro del movimiento estudiantil es un ejemplo de lo observado por otras autoras en América Latina.

\begin{abstract}
Al explorar lo político en los movimientos sociales, debemos ver la política como algo más allá que el conjunto de actividades específicas (votar, hacer campaña o lobby) que ocurren en los espacios institucionales claramente delimitados, tales como parlamentos e partidos; ella debe ser vista como abarcando también luchas de poder realizadas en una amplia gama de espacios culturalmnete definidos como privados, sociales, económicos, culturales y así por delante. (ALVAREZ; DAGNINO; ESCOBAR, 2000, p. 29).
\end{abstract}

Teniendo en consideración este proceso, pensamos que la propuesta y experiencias que prefiguran el control comunitario de la educación son síntesis de este proceso político y social, no obstante, se trata de un proceso limitado y lleno de problemáticas pero también de saberes que podrían aportarnos en la construcción de una educación contra-hegemónica. A continuación presentamos los principales hallazgos obtenidos tras una revisión bibliográfica y documental sobre la propuesta del control comunitario de la educación. Los tópicos descritos corresponden a la definición del concepto, elementos centrales de la gestión educativa propuesta, la disputa de la educación al Estado, la resignificación de la democracia y la articulación territorial.

\title{
6 EL CONTROL COMUNITARIO
}

El control comunitario es un concepto acuñado por primera vez como tal, por parte de los y las estudiantes secundarios/as agrupados en la Asamblea Coordinadora de Estudiantes Secundarios de Chile (ACES, 2012). El proceso de construcción de este concepto tuvo lugar en las grandes movilizaciones por la educación del año 2011, momento en que el movimiento estudiantil, demandaba una educación gratuita, sin lucro, pública y de calidad. Sin embargo estas peticiones resultaban insuficientes frente al empuje del movimiento popular y la composición de clase baja y explotada que tenía el movimiento estudiantil. Es a partir de aquello que comienzan a surgir distintas experiencias que proponen levantar una propuesta educativa, que fuera más allá de la lógica peticionista que tenían los movimientos sociales posteriores a la dictadura y durante todo el proceso de transición política. Con esto, comienzan a gestarse distintos esfuerzos por construir esta nueva propuesta que adoptó por nombre "Propuesta Educacional: La educación que queremos" y donde se termina acuñando el concepto de control comunitario.

Sin embargo, el control comunitario no debe ser entendido como una demanda nueva, sino que histórica y sustancial del movimiento popular chileno, pues ha sido levantada en diferentes momentos de la historia y desarrollada por varias experiencias educativas del campo popular. De esa forma, 
aunque con nombres diferentes, su eje principal siempre ha consistido en ser una herramienta para la construcción de poder popular (ACES, s/f).

El control comunitario puede ser entendido como una herramienta de los sectores oprimidos y populares para la construcción de espacios participativos en todos los ámbitos en los que nos desenvolvimos cotidianamente. Este concepto tuvo su primera conceptualización en la Propuesta Educacional de la ACES en el año 2011, en donde su cuarto punto nos plantea lo siguiente:

Sistema educativo descentralizado, participativo y con control comunitario. Se propone un sistema escolar gestionado descentralizadamente por organismos educativos estatales con participación de la comunidad como reemplazo al actual sistema de educación municipalizada (ACES, 2012, p. 12).

Ya en este apartado podemos observar la intención que tiene el control comunitario por abordar al sistema educativo de tal forma en que sean las comunidades las que tengan participación tanto en la gestión y administración como los proyectos educativos de los establecimientos escolares. Como lo veremos más adelante, este proceso tiene relación con la capacidad de organizar y guiar a las comunidades educativas en un proceso de enfrentamiento contra-hegemónico con el Estado y sus superestructuras, que tienen control e influencia en la educación.

Por otro lado, este punto dentro de la Propuesta Educacional ACES tiene varias bajadas concretas que nos permite evidenciar que existe un análisis de la realidad por parte de esta organización y la posibilidad efectiva de implementar este concepto.

La propuesta es descentralizar efectivamente los recursos, funciones, capacidades y responsabilidades dentro de los establecimientos escolares. Para esto se debe implementar la participación efectiva de la comunidad escolar y territorial en la gestión y la definición de contenidos curriculares, por medio de instancias resolutivas y vinculantes. Consejos escolares y territoriales de educación. Además es necesario potenciar las capacidades profesionales y técnicas de los actores de la comunidad y terminar con la lógica de externalización de servicios. Se debe contar con apoyos técnicos suficientes: curriculistas, psicólogos, docentes para talleres, asistentes sociales, investigadores, etc. El control comunitario se propone democratizar los reglamentos internos y manuales de convivencia. Por consiguiente, las escuelas del Estado deben estar bajo el control de las comunidades educativas (ACES, s/f).

Como se plantea anteriormente, el control comunitario, tiene relación con ser una herramienta de la clase trabajadora y el pueblo para generar espacios de administración, gestión, organización y posteriormente control en distintos ámbitos de la vida en sociedad. Uno de esos espacios es la educación en sus diferentes niveles y formas, la cual siempre ha estado en manos y al servicio de la clase dominante, primero con la Iglesia, posteriormente en manos de un Estado hegemónico y en la actualidad, en el control de grandes conglomerados económicos y de los denominados empresarios de la educación (ACES, 2012). Es por esto que en el desarrollo del movimiento social siempre ha estado 
presente la idea de que la clase trabajadora tome por cuenta y mano propia la educación de sus hijos, existiendo experiencias históricas al respecto.

La apuesta organizacional es entendida como un proceso que tiene distintos niveles y desarrollo a lo largo de su construcción, ya que en la actualidad existe una heterogeneidad respecto a los distintos contextos y escenarios en donde la clase trabajadora se desempeña, por lo que se niega la idea de una fórmula sobre el control comunitario porque se entiende que este proceso debe ser inclusivo e integral respecto a la diversidad de "comunidades autónomas" que existen. Éste proceso supone que cada espacio genere la participación y la organización que estime conveniente.

Con respecto a lo organizacional y, fundamentalmente, en cuanto a lo que tiene que ver con la gestión dentro del control comunitario, se entiende que deben ser los estudiantes, profesores, funcionarios no docentes y apoderados quienes deben administrar y gestionar las instituciones educativas (ACES, s/f). Lo importante de decidir tomar control de la gestión se refiere a la disputa por la orientación y la forma de impartición del conocimiento. La educación pública desde sus orígenes ha sido gestionada por las clases dominantes, puesto que su sentido y metodologías han sido orientados por la visión del mundo y los intereses de la élite. La gestión de la educación por parte de las comunidades organizadas es una forma de enfrentar la reproducción de la ideología dominante y la construcción de la contra-hegemonía tanto ideológica, política y cultural la cual le disputara el poder al Estado (CENTRO ALERTA, s/f).

Se propone entonces, desde el control comunitario, una gestión descentralizada por organismos educativos estatales, la participación de la comunidad organizada como reemplazo al sistema actual municipalizado de la educación formal y la presencia de todos los estamentos en los Consejos Superiores y en las decisiones presupuestarias al interior de las casa de estudio de la educación superior. El control comunitario no se puede entender como autogestión, sino más bien como la construcción de una educación que a partir de recursos que el Estado otorga debe satisfacer las necesidades del pueblo (ACES, 2012). Por otro lado, otras organizaciones que reivindican el control comunitario sí reconocen en este un componente autogestivo (RECUPERACCIÓN, 2017), aunque debemos destacar que se trata de otro tipo de experiencias ajenas al mundo educativo formal.

El control comunitario también apuesta a desarrollar el proceso de "reconstitución del tejido social", que va de la mano con lo que se denomina como la "resignificación de la democracia". Este ámbito a su vez se refiere a generar espacios de participación y de reunión de los distintos actores presentes, en este caso, en el proceso educativo, en donde la interacción entre ellos debe darse bajo las lógicas de la solidaridad y la igualdad, entendiéndose como pertenecientes a una misma comunidad (ACES, s/f). En este proceso se apuesta a conformar una articulación, tanto al interior como al exterior del establecimiento educativo, que genere una vinculación directa y horizontal respecto a los asuntos de este y la comunidad organizada (RECUPERACCIÓN, 2017). 
Como reemplazo de una práctica democrática obsoleta en términos de participación ciudadana que se distancia con la realidad de la clase trabajadora, es que surge la participación directa y vinculante, a través de la asamblea como el espacio de encuentro y discusión de los miembros de la comunidad, en donde se deciden y proponen el quehacer, en lo cotidiano y doméstico pero, también, en los lineamientos pedagógicos - políticos de los establecimientos escolares. Entendemos que este proceso no debe ser local ni particular, sino que se debe generar a nivel nacional pero de forma articulada con lo local y regional.

\section{CRÍTICAS Y DESAFÍOS DEL CONTROL COMUNITARIO}

El planteamiento de esta forma de abordar la educación no se encuentra exento de contradicciones, ya que nos encontramos en un proceso de desarrollo de un sistema capitalista muy profundo, que en gran medida hace casi imposible el desenvolvimiento y la construcción del control comunitario. Por otra parte, la experiencia estudiantil, gracias al empuje del movimiento feminista, también ha desarrollado otras discusiones incorporando nuevas demandas como la educación no sexista que además de tensionar las relaciones cotidianas de los territorios en resistencia provoca transformaciones en las reivindicaciones.

Una de las principales problemáticas tiene que ver con lo anteriormente expuesto y que el proceso de construcción del control comunitario no se encuentre a la par de una lucha constante y por otros medios contra el capitalismo, es decir, este se encuentra aislado y aún restricto al campo educativo. Además, el movimiento social, tomando en cuento los últimos años, no ha logrado salir de una visión peticionista en lo que respecta a las mejoras de su vida cotidiana y, aunque el control comunitario signifique un avance en ese sentido, tampoco tiene una visión sobre la fase previa que debiese darse para que se pueda desarrollar de forma plena, por lo cual carece de sustento para la construcción de un control real de las comunidades sobre el proceso educativo.

A su vez, el control comunitario, tiene varias deficiencias en cuanto a definiciones de la administración, así como también políticas. En ese sentido, no queda claro quién debe dirigir el proceso del control comunitario de un establecimiento escolar, por ejemplo, si la comunidad territorial aledaña o los propios trabajadores, junto a estudiantes, apoderados, o sea, los sujetos que se encuentran directamente vinculados al establecimiento escolar. En esa misma línea, existe el cuestionamiento en torno a cómo con el control comunitario efectivamente asegurar el manejo de la educación, así como logra el control de los medios de producción en una fábrica. 0 sea, si esta táctica política es pertinente para un campo diferente al del productivo.

Sin embargo, el desafío que propone hoy el control comunitario tiene que ver principalmente con una democratización de las instituciones educativas y al menos poner en la palestra la discusión 
sobre quiénes deben ser los que controlen y lleven a cabo en su máxima expresión, la gestión, participación, organización y poder dentro de los establecimientos educacionales. Por lo mismo es que, el desafío del control comunitario, en la lógica educativa actual, tiene relación con levantar demandas que avancen en generar espacios más participativos para la comunidad y que favorezcan la inclusión de esta en las decisiones que se toman y que tengan que ver con su propia educación.

\section{REFERÊNCIAS}

ALONSO, A. As teorias dos movimentos sociais: um balanço do debate. Lua Nova - Revista de Cultura Política [online]. n. 76, p. 49-86, 2009. Disponible en: <http://dx.doi.org/10.1590/S010264452009000100003>. Acceso en: 15 mar. 2017.

ASSAÉL, J. et al. La empresa educativa chilena. Educação \& Sociedade, v. 32, n. 115, p. 305-322, 2011.

ALVARES, S.; DAGNINI, E.; ESCOBAR, A. Introdução. O cultural e o político nos movimentos sociais latino-americanos. In: ALVARES, S.; DAGNINI, E.; ESCOBAR, A. (Orgs). Cultura e política nos movimentos sociais latino-americanos. Belo Horizonte: Editora UFMG, 2015. p. 15-57.

CALDERÓN, F.; JELIN, E. Clases sociales y movimientos sociales en América Latina. Perspectivas y realidades. Revista Proposiciones, 14, p. 173-189, 1987. Disponible en: <http://www.sitiosur.cl/publicacionescatalogodet alle.php?PID $=2977 \&$ doc $=\& \mathrm{lib}=\mathrm{Y} \& \mathrm{rev}=\mathrm{Y} \& \mathrm{art}=\mathrm{Y} \& \mathrm{~d}$ oc1 $=$ Y\&vid $=$ Y\&autor $=\&$ coleccion $=\&$ tipo $=$ ALL\&nun ico $=15000014>$. Acceso en: 26 oct. 2018.

CENTRO ALERTA; OPECH. Contextualización 2011. In GONZÁLEZ, J.; SÁNCHEZ, R.; SOBARZO, M. (eds). 2011: Aportes para interpretar una década de lucha por autoeducación. Santiago: Editorial Quimantú, 2012.p. 17-21.

DELLA PORTA, D. Social Movements in times of austerity: bringing capitalism back into protests analysis. Cambridge: Polity Press, 2015.

DUARTE, C. El Mochilazo del 2001 instala la discusión sobre lo que se considera como derechos: Entrevista a Claudio Duarte 1/3, 2013. Disponible en:

<https://juventudsedej.wordpress.com/2013/09 /24/el-mochilazo-del-2001-instala-la-discusionsobre-lo-que-se-considera-como-derechosentrevista-a-claudio-duarte-13/> Acceso en: 26 oct. 2018.

FAURÉ, D. Las prácticas de (auto) educación popular en Chile post-dictadura y la propuesta del 'Control Comunitario'. Revista Educación de adultos y procesos formativos, n. 3, 2016. Disponible en: $<$ http://www.educaciondeadultosprocesosformat ivos.cl/index.php/revistas/revista-n-3/33-laspracticas-de-auto-educacion-popular-en-chilepost-dictadura-y-la-propuesta-del-controlcomunitario> Acceso en: 26 oct. 2018.

GARCÉS, M. El despertar de la sociedad. Los movimientos sociales en América Latina y Chile. Santiago: LOM Ediciones, 2012.

GAUDICHAUD, F. Las fisuras del neoliberalismo maduro chileno. Ciudad Autónoma de Buenos Aires: CLACSO, 2015.

GONZÁLEZ, J. Ciudadanía juvenil en el Chile postdictadura. El movimiento secundario del año 2006 y las organizaciones de auto-educación popular en Santiago de Chile. In: REDONDO, J.; MUÑOZ, L. Juventud y enseñanza media en Chile del bicentenario. Antecedentes de la revolución pingüina. Santiago: Imprenta Salesianos, 2009. p. 394-438.

GUTIÉRREZ, R. Pistas reflexivas para orientarnos en una turbulenta época de peligro. In: GUTIÉRREZ, R. (Ed). Palabras para tejernos, resistir y transformar en la época que estamos viviendo. Santiago: Pez en Árbol/Editorial Quimantú, 2011. p. 13-35.

GUTIÉRREZ, T.; CAVIEDES, C. Revoluión Pinguina. La primera gran movilización del Siglo XXI en Chile. Santiago: Editorial Ayun, 2010.

INZUNZA, J. La asociatividad juvenil en los liceos públicos chilenos: la disolución de los centros de alumnos. In: REDONDO, J.; MUÑOZ, L. Juventudy enseñanza media en Chile del bicentenario. Antecedentes de la revolución pingüina. Santiago: Imprenta Salesianos, 2009. p. 374-393.

MARQUES, A.; LUCON, I. (2017). Reflexões sobre globalização e crise estrutural do capital: história econômica e crítica social. In: FILHO, P.; NOVAES, H.; Macedo, R. (Org). Movimentos sociais e crises contemporâneas à luz dos clássicos do materialismo crítico. Uberlândia: Navegando Publicações, 2017. p. 196-216.

MCADAM, D. Orígenes terminológicos, problemas actuales, futuras líneas de investigación. In: MCADAM, D.; MCCARTHY, J.; ZALD, M. (eds). Trad. Sandra Chaparro. Movimientos sociales: 
perspectivas comparadas. Madrid: Istmo, 1999. p. 49-70.

MCCARTHY, J. Adoptar, adaptar e inventar límites y oportunidades. In: MCADAM, D.; MCCARTHY, J.; ZALD, M. (eds). Trad. Sandra Chaparro.

Movimientos sociales: perspectivas comparadas. Madrid: Istmo, 1999. p. 205-220.

MUÑOZ, V. Movimiento Social Juvenil y Eje Cultural. Dos contextos de reconstrucción organizativa. Última década, v. 10, n. 17, p. 41 - 64, 2002.

Disponible en:

<https://scielo.conicyt.cl/scielo.php?script=sci_ar ttext\&pid=S0718-22362002000200003> Acceso en: 01 ago. 2017.

OLAVE, P. Chile: Neoliberalismo, pobreza y desigualdad social. México: Instituto de Investigaciones Económicas, UNAM, 2003.

OLIVEIRA, F. A dominação globalizada: estrutura e dinâmica da dominação burguesa no Brasil. In: BASUALDO, E. M.; ARCEO, E. (Org). Neoliberalismo y sectores dominantes: tendencias globales $\mathrm{y}$ experiencias nacionales. Buenos Aires: Consejo Latinoamericano de Ciencias Sociales - CLACSO, 2006. p. 265-291.

OBSERVATORIO CHILENO DE POLITICAS

EDUCATIVAS. De actores secundarios a estudiantes protagonistas. Santiago: Ediciones Quimantú, 2010.

REDONDO, J. El experimento chileno en educación. ¿Conduce a mayor equidad y calidad en educación? Última Década, v. 13, n. 22, p. 95-110, 2005.

SILVA, B. La revolución pingüina y el cambio cultural en Chile. Centro de Estudios sobre Cultura, Política y Sociedad. CLACSO, 2007. Disponible en: <http://www.ub.edu/cecups/es/publicaciones/la -revoluci\%C3\%B3n-ping\%C3\%BCina-y-elcambio-cultural-en-chile> Acceso en: 23 sept. 2017.

SOARES, H. Rebeliões e ocupações de 2011. In: HARVEY, D.; TELES, E.; SADER, E.; ALVES, G.; SOARES, H.; CARNEIRO, H.; WALLERSTEIN, I.; PESCHANSKI, J.; DAVIS, M.; ŽIŽEK, S.; ALI, T.; SAFATLE, V. Occupy. Movimentos de protesto que tomaram as ruas. São Paulo: Boitempo e Carta Maior, 2012. p. 7-14.

TARROW, S. Poder en Movimiento. Los movimientos sociales, la acción colectiva y la política. Madrid: Alianza Editorial, 1997.

TILLY, C. Movimentos sociais como política. Revista Brasileira de Ciência Política, no 3, p. 133-160, 2010.

VALENZUELA, E. Tomándose la educación, con sus propias ideas y manos. In: GONZÁLEZ, J.; SÁNCHEZ, R.; SOBARZO, M. (eds). 2011: Aportes para interpretar una década de lucha por autoeducación. Santiago: Editorial Quimantú, 2012. p. 131-135.
VILLALOBOS, C.; QUARESMA, M. Sistema escolar chileno: características y consecuencias de un modelo orientado al mercado. Convergencia, v. 22, n. 69, p. 63-84, 2015. Disponible en:

<http://www.scielo.org.mx/scielo.php?script=sci_ arttext\&pid=S1405-

14352015000300063\&lng=es\&tlng=es $>$ Acceso en: 01 ago. 2017.

ZIBECHI, R. Los movimientos sociales latinoamericanos: tendencias y desafíos. OSAL: Observatorio Social de América Latina - CLACSO, año III, n. 09, p. 185-188, 2003.

. Autonomías y emancipaciones. América

Latina en movimiento. Lima: Programa Democracia y Transformación Global y Fondo Editorial de la Facultad de Ciencias Sociales, UNMSM, 2007. . Dispersar el poder. Los movimientos como poderes antiestatales. 2. Ed. Santiago: Editorial Quimantú, 2011. . Vientos sobre el progresismo. Cultivando el SumakKawsay. Santiago: Editorial Quimantú, 2014.

\section{Documentos, publicaciones y otros analizados}

ASAMBLEA COORDINADORA DE ESTUDIANTES SECUNDARIOS. Propuesta para la educación que queremos. 2012. Disponible en: <http://www.opech.cl/comunicaciones/2012/05 /aces_final.pdf> Acceso en: 02 nov. 2018.

Disponible en: Minuta 1 Control Comunitario. s/f.

<http://www.opech.cl/comunicaciones/2013/04 /minuta_control_comunitario.pdf $>$ Acceso en: 27 oct. 2018.

CENTRO ALERTA. Documento para la discusión. Control comunitario: una perspectiva en construcción... s/f. Disponible en: <http://www.opech.cl/comunicaciones/2013/07 /control_comunitario_perspectiva_construccion.p df> Acceso en: 27 oct. 2018.

OPECH. Control comunitario. In: YAÑEZ, R.; VISOSTKY, J. Tomar la escuela. Santiago: Quimantú, 2014. p. 43-53.

RECUPERACCIÓN: Cuando lo público no es comunitario. Dirección: Ricardo Pérez Mendez. Producción y Guión: Ricardo Madrid Flores, 2017. Disponible en:

<https://www.youtube.com/watch?v=Y_LmCTon 530> Acceso en: 27 oct. 2018. 